\title{
Impact of a screen, triage and treat program for identifying chronic disease risk in Indigenous children
}

\author{
Kara L. Frejuk BSc, Oksana Harasemiw MSc, Paul Komenda MD, Barry Lavallee MD, Lorraine McLeod RN BN, \\ Caroline Chartrand RN, Michelle Di Nella MA, Thomas W. Ferguson MSc, Heather Martin BSc, Brandy Wicklow MD MSc, \\ Allison B. Dart MD MSc
}

Cite as: CMAJ 2021 September 13;193:E1415-22. doi: 10.1503/cmaj.210507

\begin{abstract}
Background: The First Nations Community Based Screening to Improve Kidney Health and Prevent Dialysis project was a point-of-care screening program in rural and remote First Nations communities in Manitoba that aimed to identify and treat hypertension, diabetes and chronic kidney disease. The program identified chronic disease in 20\% of children screened. We aimed to characterize clinical screening practices before and after intervention in children aged $10-17$ years old and compare outcomes with those who did not receive the intervention.
\end{abstract}

Methods: This observational, prospective cohort study started with community engagement and followed the principles of ownership, control, access and possession (OCAP). We linked participant data to administrative data at the Manitoba Centre for Health Policy to assess rates of primary care and nephrology visits, disease-modifying medication prescriptions and laboratory testing (i.e., glycosylated hemoglobin $\left[\mathrm{HbA}_{1 \mathrm{c}}\right]$, estimated glomerural filtration rate [eGFR] and urine albumin- or protein-tocreatinine ratio). We analyzed the differences in proportions in the 18 months before and after the intervention. We also conducted a 1:2 propensity score matching analysis to compare outcomes of children who were screened with those who were not.

Results: We included 324 of 353 children from the screening program $(43.8 \%$ male; median age $12.3 \mathrm{yr}$ ) in this study. After the intervention, laboratory testing increased by $5.8 \%$ (95\% confidence interval $[\mathrm{Cl}]$ $1.1 \%$ to $10.1 \%)$ for $\mathrm{HbA}_{1 \mathrm{c}}$, by $9.9 \%(95 \% \mathrm{Cl}$ $4.2 \%$ to $15.5 \%$ ) for eGFR and by $6.2 \%$ (95\% Cl $2.3 \%$ to $10.0 \%$ ) for the urine albumin- or protein-to-creatinine ratio. We observed significant improvements in laboratory testing in screened patients in the group who were part of the program, compared with matched controls.

Interpretation: Chronic disease surveillance and care increased significantly in children after the implementation of a point-of-care screening program in rural and remote First Nation communities. Interventions such as active surveillance programs have the potential to improve the chronic disease care being provided to First Nations children.

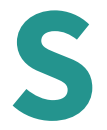

ubstantial health disparities exist between Indigenous and non-Indigenous people in Canada. The prevalence of diabetes and chronic kidney disease (CKD) among Indigenous people in Canada is $20 \%$ and $25.5 \%$, respectively, which is twoto fivefold higher than the general population. ${ }^{1-3}$ Indigenous peoples are also at higher risk of progression to kidney failure as adults $^{4-6}$ and in childhood. ${ }^{7}$ Risk factors for CKD, such as diabetes, hypertension and obesity, manifest earlier in life and contribute to higher lifetime risk of complications. ${ }^{8}$ These risk factors are more prominent in Indigenous communities given the systemic inequalities that affect them. ${ }^{9,10}$

This burden of chronic disease may be mitigated by efforts to increase access to preventive care and implementation of programs to increase early diagnosis, education and treatment. Biomarkers for CKD in Indigenous youth are not entirely persistent in the early stages of disease. ${ }^{11,12}$ Early diabetes and CKD are often asymptomatic, and the opportunity to intervene is more impactful early in the disease course. One strategy to increase the likelihood of timely intervention is screening. The Diabetes Canada guidelines suggest screening for diabetes biennially for Indigenous children. ${ }^{13}$ Although Indigenous children are at higher risk of CKD, irrespective of diabetes status, guidelines do not currently exist for routine CKD screening in children.

Around the world, screening for CKD in children is a controversial issue, given the uncertainty of its effectiveness. ${ }^{14}$ In Canada, screening for CKD in the general pediatric population 
is not currently recommended. ${ }^{15}$ However, this approach does not consider screening in high-risk populations with reduced access to primary care resources. Manitoba has the highest rates of CKD in Canada, with a prevalence of 1704 per million population, compared with the overall rate of 1372 per million population in Canada. ${ }^{16}$ The Indigenous population is over-represented, with progression to kidney failure 8 years sooner than non-Indigenous people. The rates of CKD among Indigenous peoples in Canada are in keeping with populations around the world in which CKD screening is recommended and has been successful. ${ }^{17}$ Our group has also shown the costeffectiveness of CKD screening in Indigenous adults. ${ }^{18}$
The First Nations Community Based Screening to Improve Kidney Health and Prevent Dialysis (FINISHED): Screen, Triage, and Treat program sought to understand the burden of kidney disease risk factors in Indigenous people 10 years of age and older, and implement an initial screening and treatment program among 13 rural and remote First Nations communities. ${ }^{19}$ This point-of-care screening intervention project identified high rates of early risk factors for kidney disease in this population, and made referrals for follow-up to either primary care (low-risk individuals) or specialty care (intermediate- or high-risk individuals), depending on screening findings. In this study, we sought to determine clinical

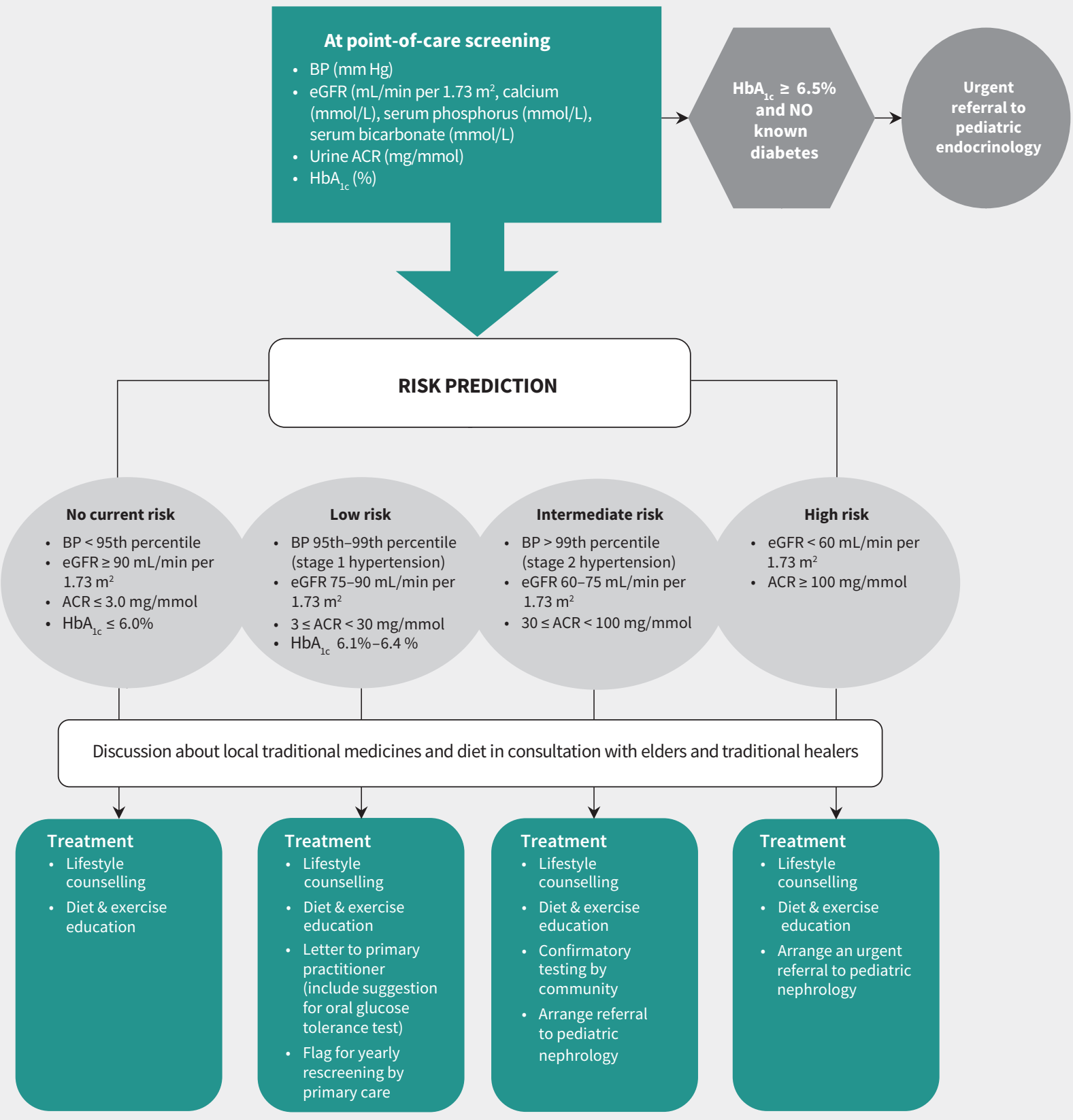

Figure 1: Pediatric paradigm for FINISHED: Screen, Triage, and Treat program. Note: $A C R=$ albumin-to-creatinine ratio, $B P=$ blood pressure, eGFR = estimated glomerular filtration rate, $\mathrm{HbA}_{\mathrm{cc}}=$ glycosylated hemoglobin . 
screening rates before and after the FINISHED intervention, and the impact of the program on chronic disease surveillance and treatment among those aged younger than 18 years.

\section{Methods}

\section{Study design}

We conducted an observational, prospective cohort study. The FINISHED project has been described previously in detail. ${ }^{19,20}$ In brief, after community engagement, mobile screening teams assessed the blood pressure, body mass index, hemoglobin $A_{1 c}$ $\left(\mathrm{HbA}_{1 \mathrm{c}}\right)$, estimated glomerular filtration rate (eGFR) and urine albumin-to-creatinine ratio on people aged 10 years and over in 9 rural and 4 remote First Nation communities in northern Manitoba between Mar. 11, 2013, and Mar. 26, 2015. The initiative used point-of-care testing equipment to complete all screening activities, and results, education and treatment plans were delivered within 1 week (usually on same day) of testing to people who were screened, according to risk-based clinical criteria (Figure 1). The screening database was subsequently deidentified and linked via scrambled identifier with administrative data housed at the Manitoba Centre for Health Policy (MCHP). ${ }^{21}$

\section{Study population}

The study population for this report included children aged 10 to 17 years at the time of screening who were screened as part of the FINISHED program and who had available administrative data for the 18 months before and after screening (Figure 2). We evaluated screening rates before the FINISHED intervention, as well as follow-up care, including visits to primary care or nephrology, disease-modifying medication prescriptions and further screening tests during the 18 months before and after screening. As a secondary analysis, we analyzed outcomes to the end of available data (Dec. 31, 2017). We identified a control group from MCHP data that did not participate in the intervention, to account for potential changes in practice that were unrelated to the screening program.

\section{Outcomes}

\section{Laboratory testing}

We used data from the Shared Health laboratory database, which contains all relevant laboratory tests from participating communities. To assess screening for diabetes, we determined the proportion of participants with at least $1 \mathrm{HbA}_{1 c}$ test. To assess screening for CKD, we determined the proportion of participants with at least 1 outpatient assessment of serum creatinine (standardized isotope dilution mass spectrometry traceable assays), urine albumin-to-creatinine ratio or urine protein-to-creatinine ratio. Estimated GFR was determined using the Chronic Kidney Disease in Children (CKiD) Schwartz equation. ${ }^{22}$ We also calculated the proportion of participants who received combinations of these tests.

\section{Primary care and nephrology visits}

We calculated the number of visits to primary care and nephrology using the physician billing database, using previously validated MCHP algorithms. ${ }^{23}$ We included only visits in outpatient settings, which could include both in-person or telehealth visits. We identified primary care and nephrologist visits using codes associated with physician specialty, using previously validated case definitions established by the MCHP. ${ }^{23,24}$ In addition, we used the International Classification of Diseases, 9th Revision to identify visits coded for diabetes, hypertension or CKD (Appendix 1, Table S1, available at www.cmaj.ca/lookup/doi/10.1503/ cmaj.210507/tab-related-content).

\section{Medication prescriptions}

We used the Drug Program Information Network (DPIN) database to identify prescriptions for antihypertensives (i.e., angiotensinconverting-enzyme inhibitors, angiotensin II receptor blockers, antiadrenergic agents, diuretics, $\beta$-blockers and calcium channel blockers), and antihyperglycemic medications (including oral therapy and insulin). We identified drugs using Anatomic Therapeutic Chemical codes, which are presented in Appendix 1, Table S2.

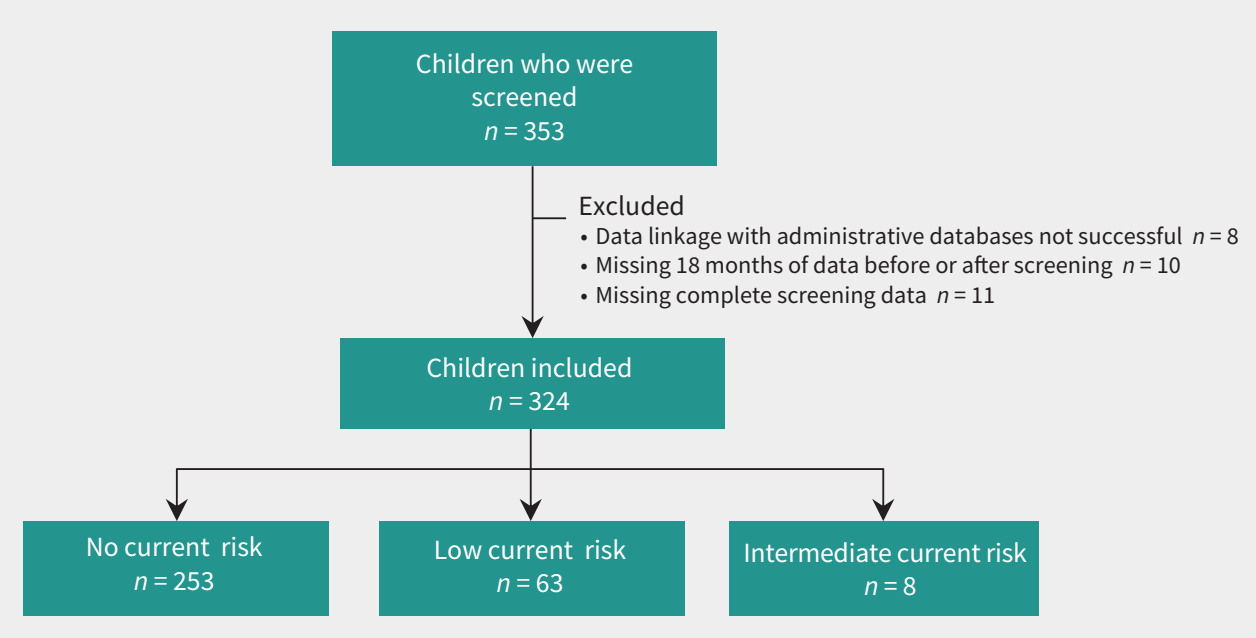

Figure 2: Study flow diagram. Note: Risk refers to current risk of progressing to kidney failure. 


\section{Data analysis}

We compared the proportions of participants undergoing laboratory testing, medication prescriptions and visits to primary care or nephrology in the 18 months before screening with those 18 months after screening. We stratified screening rates by rural or remote (i.e., fly-in access or by winter road only) community status. We used the date of screening as the index date for all analyses. We suppressed cell sizes with fewer than 6 individuals to protect individual anonymity.

To isolate the effect of the FINISHED intervention, we used a propensity score analysis to assemble a comparison group of individuals younger than 18 years from Indigenous communities that were not offered the point-of-care screening. For the comparison group, we assigned a pseudo-screening date based on the frequency distributions of time from the start to the end of the screening period. ${ }^{25,26}$ Variables used in the propensity score model included age, sex, rural or remote dwelling location, and comorbidities, including chronic pulmonary disease, diabetes and renal disease. We matched individuals 2-to-1 (comparison-to-intervention) without replacement within a caliper distance of $20 \%$ of the pooled standard deviation of the logit of the propensity score. ${ }^{27}$ We considered a greater than $10 \%$ standardized difference in a characteristic between groups after matching to be unbalanced.
For each of the analyses, we constructed difference-indifferences models to estimate group differences in change of outcome frequency over time. ${ }^{28,29}$

\section{Ethics approval}

The FINISHED screening project was approved by the Health Research Ethics Board at the University of Manitoba (HS16070), as well as the Diabetes Integration Project Board of Directors, relevant Tribal Council Leaders and the participating communities. Every effort was made to follow Indigenous research principles of Ownership, Control, Access and Possession (OCAP). ${ }^{30}$

\section{Results}

Of the 353 Indigenous children aged 10 to 17 that were initially screened in the FINISHED project, 334 had available administrative data and are included in this report. The median follow-up time after screening was 4.64 (interquartile range $4.17-5.07$ ) years. The median age was 12 years, and 182 (56.2\%) were female. Of the 324 participants, 133 (41.0\%) were from rural communities and 191 (59.0\%) were from remote communities. The demographics and screening characteristics are displayed in Table 1. We identified 648 control patients that were well matched based on age, sex, dwelling location and prevalence of chronic disease (Appendix 1, Table S3).

\section{Table 1: Participant characteristics at the time of point-of-care screening in the FINISHED screening program}

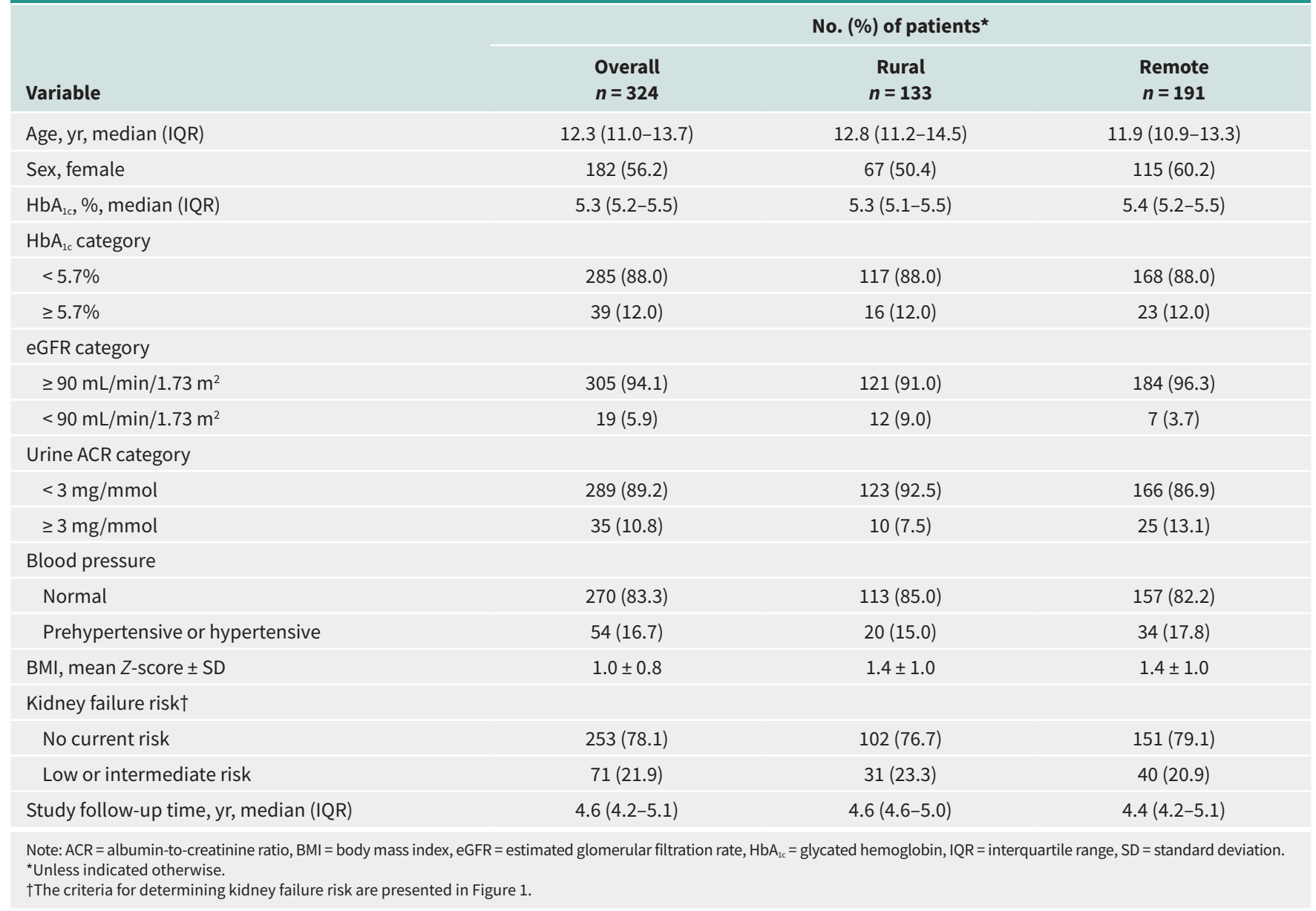




\section{Rates of clinical screening and health care visits}

The rates of laboratory testing, medication prescriptions and follow-up visits are presented in Table 2. Comparisons with the propensity matched controls are presented in Table 3.

\section{Laboratory testing}

The proportion of individuals who received at least 1 eGFR test increased from $11.4 \%$ to $21.3 \%$ in the 18 months after FINISHED (95\% confidence interval $[\mathrm{Cl}] 4.2 \%$ to $15.5 \%$ ). Compared with the control group, there was a crude risk difference of $7.1 \%$ in eGFR testing ( $95 \% \mathrm{Cl} 0.9 \%$ to $11.1 \%)$. Testing of $\mathrm{HbA}_{1 \mathrm{c}}$ increased from $6.8 \%$ to $12.4 \%$ (95\% Cl $1.1 \%$ to $10.1 \%$ ). There was a $4.8 \%$ crude risk difference in the intervention group compared with the control ( $95 \% \mathrm{Cl} 0.2 \%$ to $9.4 \%$ ). The rates of urine testing for calculation of the albumin- or protein-to-creatinine ratio increased from $3.7 \%$ to $9.9 \%$ (95\% Cl $2.3 \%$ to $10.0 \%)$. Of the 35 children with an abnormal urine albumin-to-creatinine ratio, $13(37.1 \%)$ had repeat testing completed. Persistent proteinuria was seen in 9 of these children. The rates of comprehensive testing, defined as at least 1 eGFR test, 1 urine albumin- or protein-to-creatinine ratio calculation, and $1 \mathrm{HbA}_{1 c}$ test, increased from $3.4 \%$ before screening to $7.1 \%$ in the 18 months after screening ( $95 \% \mathrm{Cl} 0.3 \%$ to $7.1 \%)$. Rates of screening continued to increase to the end of the follow-up available in the database (Dec. 31, 2017) (Table 2). Notably, the intervention group had a $6.3 \%$ increased frequency of urine albumin- or protein-to-creatinine ratio calculations compared with the control group (95\% Cl 2.6\% to $10.0 \%$ ) (Table 3).

Table 2: Rates of outpatient testing, disease-modifying medication prescriptions, and primary care and nephrology visits in the 18 months before and after point-of-care screening in the FINISHED program

\section{No. $(\%)$ of patients}

Variable
$\geq 1$ eGFR test
$\geq 1$ urine $A C R$ or $P C R$
$\geq 1 \mathrm{HbA}_{1 \mathrm{c}}$ test
$\geq 1$ eGFR and urine ACR or PCR
$\geq 1$ eGFR and $\mathrm{HbA}_{1 \mathrm{c}}$ and urine ACR or PCR
$\geq 1$ antihypertensive
$\geq 1$ antihyperglycemic
$\geq 1$ primary care visit
$\geq 1 \mathrm{ICD}$ diagnostic code recorded for either
diabetes, hypertension or renal disease
$\geq 1$ nephrology visit

$\geq 1$ nephrology visit
No. $(\%)$ of patients after screening, followed to Dec. 31, 2017 $(95 \% \mathrm{CI})^{*}$

$$
\begin{gathered}
140(43.2) \\
48(14.8) \\
76(23.5) \\
46(14.2) \\
37(11.4) \\
15(4.6) \\
11(3.4) \\
257(79.3) \\
33(10.2)
\end{gathered}
$$

\begin{tabular}{|c|c|c|c|c|c|c|c|}
\hline \multirow[b]{2}{*}{ Variable } & \multicolumn{2}{|c|}{$\begin{array}{l}\text { No. }(\%) \text { of intervention group } \\
\qquad n=324\end{array}$} & \multirow[b]{2}{*}{$\begin{array}{l}\% \text { difference } \\
(95 \% \mathrm{CI})^{\star}\end{array}$} & \multicolumn{2}{|c|}{$\begin{array}{c}\text { No. }(\%) \text { of control group } \\
n n=648\end{array}$} & \multirow[b]{2}{*}{$\begin{array}{l}\% \text { difference } \\
(95 \% \mathrm{CI})^{\star}\end{array}$} & \multirow{2}{*}{$\begin{array}{c}\text { Difference in \% } \\
\text { change, } \\
\text { intervention v. } \\
\text { control groups } \\
(95 \% \mathrm{Cl}) \dagger\end{array}$} \\
\hline & $\begin{array}{l}\text { Before } \\
\text { screening }\end{array}$ & $\begin{array}{c}\text { After } \\
\text { screening }\end{array}$ & & $\begin{array}{c}\text { Before } \\
\text { screening }\end{array}$ & After screening & & \\
\hline$\geq 1 \mathrm{eGFR}$ test & 37 (11.4) & $69(21.3)$ & 9.9 (4.2 to 15.5$)$ & $56(8.6)$ & 74 (11.4) & $2.8(-0.5$ to 6.1$)$ & 7.1 (0.9 to 11.1$)$ \\
\hline$\geq 1$ urine $\mathrm{ACR}$ or $\mathrm{PCR}$ & $12(3.7)$ & $32(9.9)$ & $6.2(2.3$ to 10.0$)$ & $18(2.8)$ & $17(2.6)$ & $-0.2(-2.9$ to 1.6$)$ & 6.3 (2.6 to 10.0$)$ \\
\hline$\geq 1 \mathrm{HbA}_{1 \mathrm{c}}$ test & $22(6.8)$ & $40(12.4)$ & $5.6(1.1$ to 10.1$)$ & $30(4.6)$ & $35(5.4)$ & 0.8 (-1.6 to 3.2$)$ & $4.8(0.2$ to 9.4$)$ \\
\hline$\geq 1$ primary care visit & $171(52.8)$ & $192(59.3)$ & $6.5(-1.1$ to 14.1$)$ & $359(55.4)$ & $355(54.8)$ & $0.6(-6.0$ to 4.8$)$ & $7.1(-2.3$ to 16.5$)$ \\
\hline$\geq 1$ nephrology visit & Suppressed & $8(2.5)$ & - & $6(0.9)$ & $7(1.1)$ & $0.2(-0.9$ to 1.2$)$ & - \\
\hline
\end{tabular}

$11(3.4)$

Note: $\mathrm{ACR}=$ albumin-to-creatinine ratio, $\mathrm{Cl}=$ confidence interval, $\mathrm{eGFR}=$ estimated glomerular filtration rate, $\mathrm{HbA}_{\mathrm{lc}}=$ glycated hemoglobin, $\mathrm{ICD}=$ International $\mathrm{Classification}$ of Diseases, $\mathrm{PCR}=$ protein-to-creatinine ratio.

${ }^{\star}$ The $\%$ difference was calculated as the $\%$ frequency in the postintervention period minus the $\%$ frequency in the preintervention period.

Table 3: Rates of outpatient testing and primary care and nephrology visits in the 18 months before and after point-of-care screening in the FINISHED program (intervention group), compared with the propensity matched control group 


\section{Primary care and nephrology visits}

The rates of visits to primary care for any reason increased from $52.8 \%$ before screening to $59.3 \%$ in the 18 months after screening $(95 \% \mathrm{Cl}-1.1 \%$ to $14.1 \%)$. This number increased further to $79.3 \%$ by Dec. 31, 2017. Rates of visits to primary care for chronic disease increased from $3.1 \%$ to $7.4 \%$ after the FINISHED program ( $95 \% \mathrm{Cl} 0.2 \%$ to $7.2 \%)$ and up to $9.9 \%$ by the end of the database. The crude risk difference between the intervention and control groups (7.1\%) was not significant (95\% Cl $-2.3 \%$ to $16.5 \%$ ). The number of nephrology visits before screening was fewer than 6 and therefore suppressed; this increased to 8 visits $(2.5 \%)$ in the 18 months after screening and 11 visits (3.4\%) when participants were followed until Dec. 31, 2017. We could not calculate the crude risk difference between the intervention and control groups because of suppressed numbers.

\section{Medication prescriptions}

The number of individuals receiving an antihypertensive medication was fewer than 6 before the FINISHED program; this increased to 9 individuals (2.8\%) in the 18 months after screening and 15 individuals (4.6\%) by Dec. 31, 2017. The number of children receiving prescriptions for antihyperglycemic medication was fewer than 6 before screening and increased to $7(2.2 \%)$ in the 18 months after screening and to 11 (3.4\%) by Dec. 31, 2017. We could not calculate the crude risk difference between the intervention and control groups because of the small number of individuals on these medications.

\section{Community remoteness}

Appendix 1, Table S4 shows the rates of laboratory testing and primary care visits for participants in rural and remote locations before and after FINISHED. The changes seen after screening were similar in rural and remote communities, with increases in eGFR testing, urine albumin- or protein-to-creatinine ratio calculations, and $\mathrm{HbA}_{1 \mathrm{c}}$.

\section{Interpretation}

After identifying a very low baseline rate of clinical screening for diabetes and CKD in at-risk Indigenous children, we found that clinical screening and primary care follow-up increased after the FINISHED: Screen, Triage, and Treat program, with increased laboratory testing, prescriptions of disease-modifying medications and follow-up in both primary and specialized care. Chronic disease screening and active surveillance strategies like the FINISHED program, now renamed Kidney Check, appeared to help narrow the care gap that Indigenous children experience. A focus on community engagement and Indigenous leadership ensured this study reflected ideologies of the communities involved.

Type 2 diabetes is an evolving health problem among Indigenous youth. ${ }^{31}$ The FINISHED screening project identified diabetes in $1.4 \%$ of individuals tested, ${ }^{19}$ more than 10 -fold higher than the national average in pediatric populations from 2010. ${ }^{31}$ The rate of diabetes has been increasing in recent years and has been identified as a major risk factor for future health concerns. Youth with type 2 diabetes have an increased risk of developing complications such as cardiovascular disease, as well as kidney disease. ${ }^{32}$ The current Diabetes Canada guidelines recommend biennial screening for type 2 diabetes in Indigenous children if they possess 1 or more additional risk factor, using a combination of $\mathrm{HbA}_{1 \mathrm{c}}$ and fasting plasma glucose. ${ }^{13}$ Diabetes Canada issued these screening recommendations because of the high rates of type 2 diabetes in this population with the hope that early initiation of treatment will lessen the complications of the disease. The same argument could be made in screening for CKD, as many types of CKD in children are treatable, and the complications, such as growth impairment, mineral and bone disease and cardiovascular disease, may be preventable with early initiation of treatment. ${ }^{33}$ Guidelines from Kidney Disease: Improving Global Outcomes (KDIGO) reflect this approach by recommending early implementation of treatment and monitoring for complications. ${ }^{34}$ Based on these guidelines, as well as the results of this study, we recommend that Indigenous children be screened biennially from the age of 10 for both of these chronic diseases.

The FINISHED project was the first of its kind to actively screen for CKD risk biomarkers in the Manitoba Indigenous population. Before this program, screening for CKD relied on testing ordered by primary care providers, with a testing rate of only $11.4 \%$. Indigenous communities in Manitoba face overwhelming acute health concerns, such as high rates of respiratory and skin infections and injuries, which limits focus on asymptomatic chronic health conditions. A greater burden of chronic disease within these communities also amplifies the care gap. The concern is late diagnosis, which limits secondary prevention interventions. Implementation of a screening program that acts in collaboration with primary care will bypass some of these problems, leading to earlier diagnosis and treatment of chronic disease. Another aspect of the FINISHED project included recommendations for further care based on risk level, with low-risk patients receiving suggestions for lifestyle intervention and flagging for yearly screening and high-risk patients receiving referral to pediatric nephrology. Children with diabetes were also referred to a pediatric diabetes clinic. The program also encouraged the implementation of preventive care in a culturally safe manner by engaging with communities and increasing knowledge around these chronic conditions. Overall, the introduction of surveillance programs will positively influence communities and act to address chronic health conditions that more severely affect Indigenous Canadians. Despite an increase in screening rates after the FINISHED program, other initiatives aiming to increase rates further are highly suggested. These strategies should include community collaboration, leading to communitydirected initiatives that will increase the sustainability of these efforts. The FINISHED project provides initial evidence that supports the implementation of a nation-wide screening initiative for First Nations people.

\section{Limitations}

Although we evaluated interventions and outcomes that occurred in the months immediately after the FINISHED program, we did 
not evaluate the long-term benefits of early identification of disease risk, such as overall impact on rates of progression to kidney failure. Although the use of MCHP administrative databases allowed assessment of follow-up for a limited period, some outcomes applied to few people and required suppression of data to maintain anonymity. Administrative health data also lacked measurements of blood pressure in the clinical setting. Another limitation is the possibility of clustering of outcomes by community.

\section{Conclusion}

The FINISHED program, now going forward as the Kidney Check program, has proved successful in increasing access to appropriate care, including increased follow-up testing, diseasemodifying medication prescriptions, and visits to both primary and specialized care for Indigenous children, who are at increased risk of diabetes and kidney disease. This study provides evidence to support the introduction of active screening initiatives in pediatric First Nations communities, including biennial screening programs in primary care clinics, to help narrow the current gaps in the health care system.

\section{References}

1. Komenda P, Lavallee B, Ferguson TW, et al. The prevalence of CKD in rural Canadian Indigenous Peoples: results from the First Nations CommunityBased Screening to Improve Kidney Health and Prevent Dialysis (FINISHED) Screen, Triage, and Treat Program. Am J Kidney Dis 2016;68:582-90.

2. Kelly L, Matsumoto C, Schreiber Y, et al. Prevalence of chronic kidney disease and cardiovascular comorbidities in adults in First Nations communities in northwest Ontario: a retrospective observational study. CMAJ Open 2019; 7:E568-72.

3. Dyck R, Osgood N, Lin TH, et al. Epidemiology of diabetes mellitus among First Nations and non-First Nations adults. CMAJ 2010;82:249-56.

4. Gao S, Manns BJ, Culleton BF, et al.; Alberta Kidney Disease Network. Prevalence of chronic kidney disease and survival among Aboriginal People. J Am Soc Nephrol 2007;18:2953-9.

5. Nash DM, Dirk JS, McArthur E, et al. Kidney disease and care among First Nations people with diabetes in Ontario: a population-based cohort study. CMAJ Open 2019;7:E706-12.

6. Thomas DA, Huang A, McCarron MCE, et al. A retrospective study of chronic kidney disease burden in Saskatchewan's First Nations People. Can J Kidney Health Dis 2018 Sept. 17. doi: 10.1177/2054358118799689.

7. Samuel SM, Foster BJ, Hemmelgarn BR, et al.; Pediatric Renal Outcomes Canada Group. Incidence and causes of end-stage renal disease among aboriginal children and young adults. CMAJ 2012;184:E758-64.

8. Kazancioglu R. Risk factors for chronic kidney disease: an update. Kidney Int Suppl (2011) 2013;3:368-71.

9. Gao S, Manns BJ, Culleton BF, et al.; Alberta Kidney Disease Network. Access to health care among status Aboriginal people with chronic kidney disease. CMAJ 2008;179:1007-12.

10. Garcia-Garcia G, Jha V; World Kidney Day Steering Committee. Chronic kidney disease in disadvantaged populations. Nephron Clin Pract 2014;128: 292-6.

11. Haysom L, Williams R, Hodson E, et al. Risk of CKD in Australian indigenous and nonindigenous children: a population-based cohort study. Am J Kidney Dis 2009;53:229-37.

12. Haysom L, Williams R, Hodson EM, et al. Natural history of chronic kidney disease in Australian Indigenous and non-Indigenous children: a 4-year populationbased follow-up study. Med J Aust 2009;190:303-6.
13. Diabetes Canada Clinical Practice Guidelines Expert Committee. Diabetes Canada 2018 clinical practice guidelines for the prevention and management of diabetes in Canada. Can J Diabetes 2018;42(Suppl 1):S1-325.

14. Hogg RJ. Screening for CKD in children: a global controversy. Clin J Am Soc Nephrol 2009;4:509-15.

15. Choosing Wisely: Five things physicians and patients should question. Itasca (IL): American Academy of Pediatrics; 2018. Available: https://www.choosingwisely. org/societies/american-academy-of-pediatrics-section-on-nephrology-and-the -american-society-of-pediatric-nephrology/(accessed 2020 July 15).

16. Manitoba Renal Program: year in review 2018-2019. KidneyHealth.ca; 2019. Available: https://www.kidneyhealth.ca/about-us/manitoba-renal-program /2018-2019-year-in-review/ (accessed 2020 July 20).

17. Hallan SI, Stevens P. Screening for chronic kidney disease: Which strategy? J Nephrol 2010;23:147-55.

18. Ferguson TW, Tangri N, Tan Z, et al. Screening for chronic kidney disease in Canadian indigenous peoples is cost-effective. Kidney Int 2017;92:192-200.

19. Dart A, Lavallee B, Chartrand C, et al. Screening for kidney disease in Indigenous Canadian children: the FINISHED screen, triage and treat program. Paediatr Child Health 2018;23:e134-42.

20. Lavallee B, Chartrand C, McLeod L, et al. Mass screening for chronic kidney disease in rural and remote Canadian first nations people: methodology and demographic characteristics. Can J Kidney Health Dis 2015;2:9.

21. Smith M, Lix LM, Azimaee M, et al. Assessing the quality of administrative data for research: a framework from the Manitoba Centre for Health Policy. J Am Med Inform Assoc 2018;25:224-9.

22. Schwartz GJ, Muñoz A, Schneider MF, et al. New equations to estimate GFR in children with CKD. J Am Soc Nephrol 2009;20:629-37.

23. Concept: ambulatory visits - physician. Winnipeg: Manitoba Centre for Health Policy; 2020. Available: mchp-appserv.cpe.umanitoba.ca/viewConcept.php ?conceptID=1069 (accessed 2020 July 23).

24. Term: nephrologist visits. Winnipeg: Manitoba Centre for Health Policy; 2020. Available: mchp-appserv.cpe.umanitoba.ca/viewDefinition.php?definitionID= 104796(accessed 2020 July 23).

25. Harvey R, Drzayich Jankus D, Mosley D, et al.; United Healthcare. Random assignment of proxy event dates to unexposed individuals in observational studies: an automated technique using SAS ${ }^{\circledR}$. MidWest SAS ${ }^{\circledR}$ Users Group; 2012. Available: http://www.mwsug.org/proceedings/2012/PH/MWSUG-2012 -PH02.pdf (accessed 2021 Jan. 4).

26. Rocque GB, Pisu M, Jackson BE, et al. Resource use and medicare costs during lay navigation for geriatric patients with cancer. JAMA Oncol 2017;3:817-25.

27. Austin PC. Optimal caliper widths for propensity-score matching when estimating differences in means and differences in proportions in observational studies. Pharm Stat 2011;10:150-61.

28. Dimick JB, Ryan AM. Methods for evaluating changes in health care policy: the difference-in-differences approach. JAMA 2014;312:2401-2.

29. Stuart EA, Huskamp HA, Duckworth K, et al. Using propensity scores in difference-in-differences models to estimate the effects of a policy change. Health Serv Outcomes Res Methodol 2014;14:166-82.

30. The First Nations principles of OCAP. Ottawa: First Nations Information Governance Centre; 2021. Available: https://fnigc.ca/ocap-training/ (accessed 2020 July 23).

31. Amed S, Dean HJ, Panagiotopoulos C, et al. Type 2 diabetes, medicationinduced diabetes, and monogenic diabetes in Canadian children: a prospective national surveillance study. Diabetes Care 2010;33:786-91.

32. Dart AB, Martens P, Rigatto C, et al. Earlier onset of complications in youth with type 2 diabetes. Diabetes Care 2014;37:436-43.

33. Becherucci F, Roperto RM, Materassi M, et al. Chronic kidney disease in children. Clin Kidney J 2016;9:583-91.

34. Kidney Disease: Improving Global Outcomes (KDIGO) CKD Work Group. KDIGO 2012 clinical practice guideline for the evaluation and management of chronic kidney disease. Kidney Int Suppl 2013;3:1-150. 
Competing interests: Paul Komenda reports support from the Canadian Institutes of Health Research, outside the submitted work. Allison Dart reports funding from the Canadian Institutes of Health Research, the Children's Hospital Research Institute of Manitoba and Research Manitoba, outside the submitted work. No other competing interests were declared.

This article has been peer reviewed.

Affiliations: Max Rady College of Medicine (Frejuk), University of Manitoba; Chronic Disease Innovation Centre (Harasemiw, Komenda, Di Nella, Ferguson, Martin), Seven Oaks General Hospital; Max Rady Department of Internal Medicine (Harasemiw, Komenda, Ferguson, Martin), University of Manitoba; First Nations Health and Social Secretariat of Manitoba (Lavallee, McLeod); Manitoba Keewatinowi Okimakanak Inc. (Lavallee, Chartrand); Department of Pediatrics and Child Health (Wicklow, Dart); Children's Hospital Research Institute of Manitoba (Wicklow, Dart), Winnipeg, Man.

Contributors: All authors contributed to the research idea and study design; Oksana Harasemiw, Paul Komenda, Barry Lavallee, Caroline Chartrand, Michelle Di Nella, Thomas Ferguson, Allison Dart and Paul Komenda acquired data, which Oksana Harasemiw analyzed. All authors interpreted the data. Kara Frejuk drafted the manuscript, and all authors revised it critically for important intellectual content, gave final approval of the version to be published and agreed to be accountable for all aspects of the work.

Content licence: This is an Open Access article distributed in accordance with the terms of the Creative Commons Attribution (CC BY-NC-ND 4.0) licence, which permits use, distribution and reproduction in any medium, provided that the original publication is properly cited, the use is noncommercial (i.e., research or educational use), and no modifications or adaptations are made. See: https://creativecommons.org/licenses/by-nc-nd/4.0/

Funding: Funding for this study was obtained through a Health Services Integration Fund grant from Health Canada (http://www.hc-sc.gc.ca.uml. idm.oclc.org/fniah-spnia/services/acces/hsif-fiss-goals-principes-eng.php).
The funder had no role in study design; data collection, analysis, and interpretation of data; writing the report; and the decision to submit this manuscript.

Data sharing: Data are available from the Manitoba Centre for Health Policy, University of Manitoba for researchers who meet the criteria for access to confidential data. Data included are housed at Manitoba Health, Diagnostic Services of Manitoba, and the First Nations Health and Social Secretariat of Manitoba. All data used in our analysis are publicly available and are held by the Government of Manitoba or contracted agencies (e.g., laboratory services). Access to this data requires approval by the University of Manitoba Health Research Ethics Board, the Government of Manitoba's Health Privacy Information Committee, and the First Nations Health and Social Secretariat of Manitoba. Legal restrictions prevent the use of these data without approval from each of the individual trustees. All of these data are provided in deidentifiable format and linked through a remote access server maintained by the Manitoba Centre for Health Policy (http://umanitoba.ca/faculties/health_sciences/medicine/ units/chs/departmental_units/mchp/). Email address: info@cpe. umanitoba.ca.

Disclaimer: The results and conclusions are those of the authors and no official endorsement by the Manitoba Centre for Health Policy, Manitoba Health, Diagnostic Services of Manitoba, or other data providers is intended or should be inferred. Data used in this study are from the Manitoba Population Research Data Repository housed at the Manitoba Centre for Health Policy, University of Manitoba and were derived from data provided by Manitoba Health, and Shared Health.

Acknowledgement: The authors acknowledge the Manitoba Centre for Health Policy for use of data contained in the Manitoba Population Research Data Repository under project \#2018/2019-50.

Accepted: June 15, 2021

Correspondence to: Allison Dart, adart@hsc.mb.ca 